Projections • 15. Practices of Health in Unruly Environments

\title{
Uncertain Space: Data Illusions and the Landscape of Illness in the 21st Century
}

\section{Sara Jensen Carr}

\section{MIT Press}

Published on: Oct 26, 2020

DOI: https://doi.org/10.1162/00c13b77.a913ea43

License: Creative Commons Attribution 4.0 International License (CC-BY 4.0). 


\section{ABSTRACT}

Disease mapping offers certainty in the face of disease outbreaks. Spatially locating illness lets the average person assess their proximity to risk and appears to tie it to specific environmental conditions. During the cholera and yellow fever epidemics of the mid- to late 1800's, disease mapping was a major factor in decisionmaking that shaped our environment. In the early 1900's when hay fever and pulmonary illness continued to wrack urban environments, narrative medical geographies provided written depictions of healthy rural regions to contrast against congested urban cities with experimental maps linking climate, topography and airflow with emerging medical knowledge of respiratory systems and circulation. However, as germ theory and vaccines decoupled environment and illness, the relationship between the physical qualities of the immediate landscape and outbreaks became less important than its simple locus. In this exploratory essay, I discuss how this decoupling has allowed for the wholesale stigmatization of both places and marginalized populations, particularly in the cases of urban blight and the AIDS epidemic. Although we are currently in an era of abundant personal and spatial data, it has proven difficult to tie contemporary public health issues back to the environment, even in cases like obesity where there are tangible connections to the physical and social characteristics of neighborhoods, due to the way this data is collected and structured. Nuanced shifts in the built environment, social determinants of health, and invisible histories of policy and environmental change have on-the-ground impacts as well, and to better understand the nature of today's landscape of disease, we must find a way to represent them spatially.

\section{Introduction}

Spatially locating the extents of disease helps to make sense of epidemics and environments that in the moment seem out of control. In this exploratory essay, I discuss how the visual depiction of illness has changed through three distinct eras. In the late $19^{\text {th }}$ and early $20^{\text {th }}$ century, diseases with direct ties to the emerging and messy urban environment such as cholera and pulmonary illness shaped concrete planning decisions as well as how we viewed urban and rural spaces in relationship to bodies. In the mid-20 $2{ }^{\text {th }}$ century era of germ theory and individualized medical treatments, the locus of disease was thought to have less relationship to external environments. As a result, spatial mapping and theories of contagion that applied to both actual and metaphorical illnesses became unmoored from the social and physical conditions that exacerbated them and instead stigmatized the behavior of those that suffered most from the afflictions at hand. How can these previous periods inform the way we depict illness in the $21^{\text {st }}$ century, especially when we have more data than ever before?

Mapping is a crucial medium in helping to understand the intersections of environment, illness, and equity. Afflictions like cholera, yellow fever, and hay fever were thought to have environmental causes; in 
documenting their incubating conditions cartographers experimented with methods of showing climatic ephemera to test hypotheses about what constituted healthy and unhealthy places. Since then, though, while health and medical geographies remain a robust academic field, spatial visualization of health and illness in popular media have become increasingly disconnected from the social, economic, and even physical factors that incubate them, especially given the more ambiguous landscapes of chronic disease. The irony is that spatial information on both environment and health has never been more available or plentiful, but this wealth of data has not necessarily made the connection between the built environment and $21^{\text {st }}$ century aliments any clearer, and in some cases even obscures it.

The interest in geolocated health data from large tech companies like Google and Amazon has grown, especially as these conglomerates seek to disrupt healthcare systems and reshape cities to suit their goals. This type of spatial information is no doubt attractive to these companies due to its apparent objectivity, but disassociated from the history of planning policy and qualitative descriptions of place presents a clear danger of only widening health inequities. This is evidenced from late $20^{\text {th }}$ century attempts to use spatial data to describe epidemics both metaphorical, such as urban blight, or actual, such as AIDS, that were influenced by social and economic conditions as much as physical ones. Although our cities and prevalent illnesses have become significantly more challenging and unrulier in contrast to the straightforward etiology of early urban cholera outbreaks, the way health is spatially visualized today appears much more controlled than its reality. To move towards equity in place and health, it is crucial we consider how to integrate socio-economic information and narratives into these spatial depictions, allow for uncertainty and experimentation, and most of all be cautious of how data on and visualizations of health are being leveraged for private interests.

\section{Origins: John Snow and environmental inventories}

The cholera epidemics that proliferated in early American and European cities were widely thought to be afflictions borne of the atmosphere, a generalized cloud of miasma that struck indiscriminately (Rosenberg 1987, p. 6). This theory had longstanding roots from Hippocrates' On Airs, Waters, and Places (400 BCE), and was further supported by American physician Valentine Seaman's 1798 copperplate maps which directly correlated deaths with sites of waste. The medium of copperplates severely limited the area of analysis, which Seaman recognized; furthermore, the map itself did not indicate an etiology of the disease, only a tenuous spatial relationship between the hypothesized origin and its outcomes (Koch 2012). English physician John Snow argued that the disease spread through contaminated water. By mapping the service area of London's Broad Street Pump and cholera cases lot by lot, he was able to convey the link to a specific environmental aberration, thirty years before the illness was tracked to the ingestion of the bacterium Vibrio cholerae by Robert Koch (Koch 2012). The Snow Map has been celebrated in both urban planning and public health as a testament to the methodologies of on-the-ground investigation combined with graphic clarity. There is a considerable amount of literature regarding the history of the Snow Map, although only a few have challenged the role of the map itself in determining and even stopping the outbreak in the neighborhood. A re-examination 
of archival records and Snow's own writings appear to show he recognized the cause of the outbreak to be the Broad Street Pump before drawing the map. Even so the narrative of the Snow Map as epochal discovery persists (McLeod 2000).

The Snow Map heralded a more analytical era of microbiology and hypothesis testing (Susser and Susser 1996), but did not immediately change the practice of medical geography. The way cholera was depicted for decades after displayed the uncertainty of epidemiology and environmental relationships. The violence of cholera, yellow fever, and other early urban diseases demanded detailed spatial investigation before their origins were known, particularly in the United States, where people were slower to accept germ theory explanations and, simultaneously, cartographers struggled to keep up with the scale and spread of cholera. In a governmental report on the cholera epidemic of 1873, which features many maps at the national, regional, and local scales, the disease is alternately shown as a black cloud radiating out from the Eastern Seaboard (as it was known to be brought to cities from ships), or as an angular hatch somewhat corresponding to riverside neighborhoods in cities such as Paducah, Kentucky (Figure 1). Other city surveys, such as in Memphis, Tennessee, show more accurate, Snow-like accounting of mortality at the neighborhood scale, showing that geographic techniques and epidemiological knowledge varied widely across the nation (Washington, DC: Government Printing Office, 1875). It is important to note, though, that these surveys were also accompanied by written qualitative accounting of the natural and built environments. An extensive report on the "Sanitary Condition of the City” published in 1865 by Council of Hygiene and Public Health of the Citizens' Association of New York, broke down the city into 29 districts, providing vivid descriptions of each landscape. Each report described conditions of soils, housing, businesses, and streets alongside the enumeration of each disease incidence, in search of any correlations between the miscellaneous detritus of the city and illness. Filthy streets, neglected garbage, overflowing sewers and drains, and neglected privies of homes were noted, and even the composition of soil is detailed, revealing a city that was a semi-solid soup of paving, geology, marsh, and dust. In some cases the landscape was made of "bricks, mortar, slate, gravel, ashes, coal-dust, street-sweepings, oyster, clam, lobster, and egg shells, pig’s hair, shavings, straw, glass, carpets, brooms, refuse materials from tanneries, crockery, bones, dead animals - as cats, rats, and dogs; shoes, boots, feathers, oyster cans, old tin roofs, tin clippings, etc. etc.” (Citizens’ Association and Council Of Hygiene And Public Health Association Of New York 1865, p. 196). 


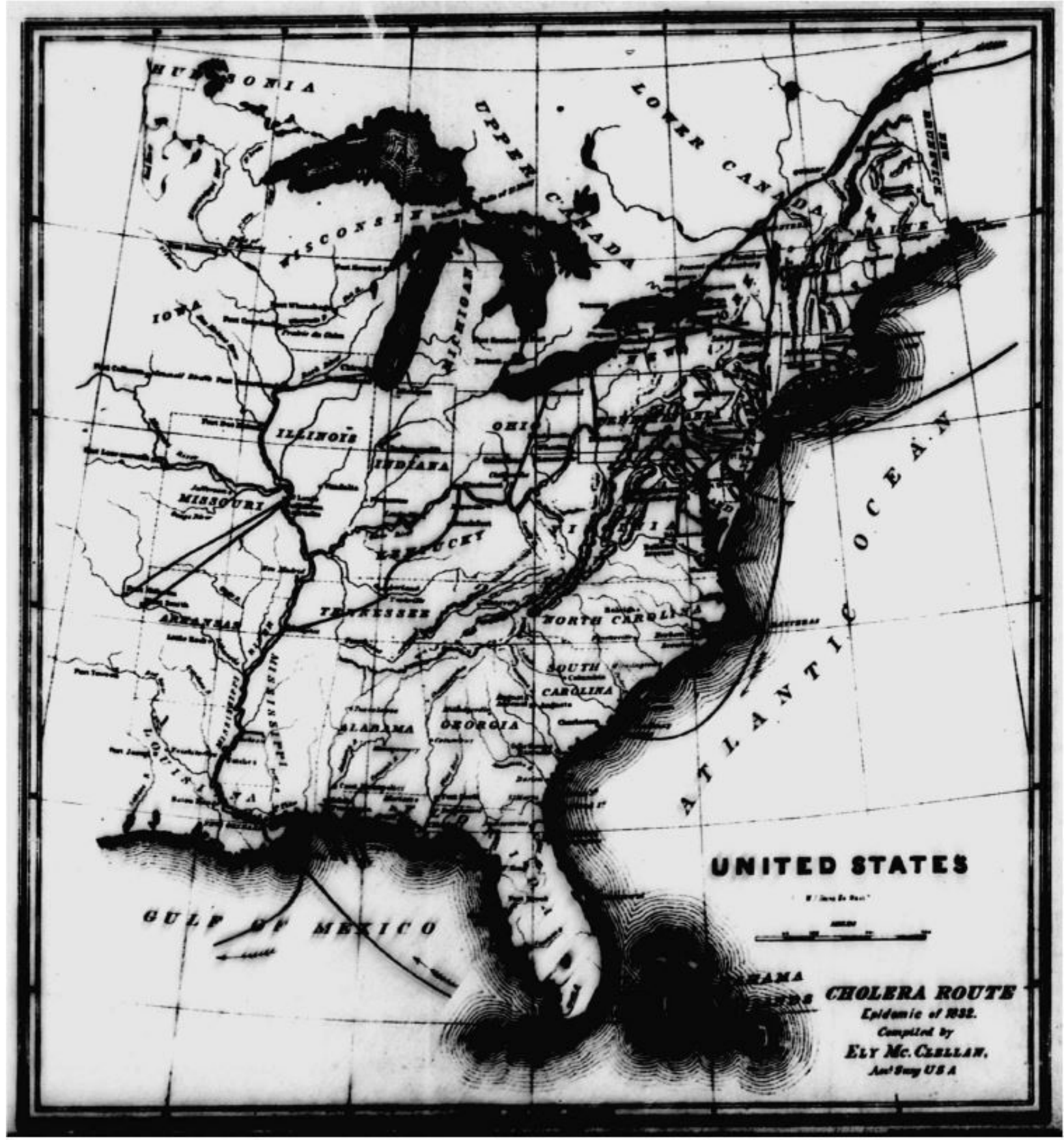




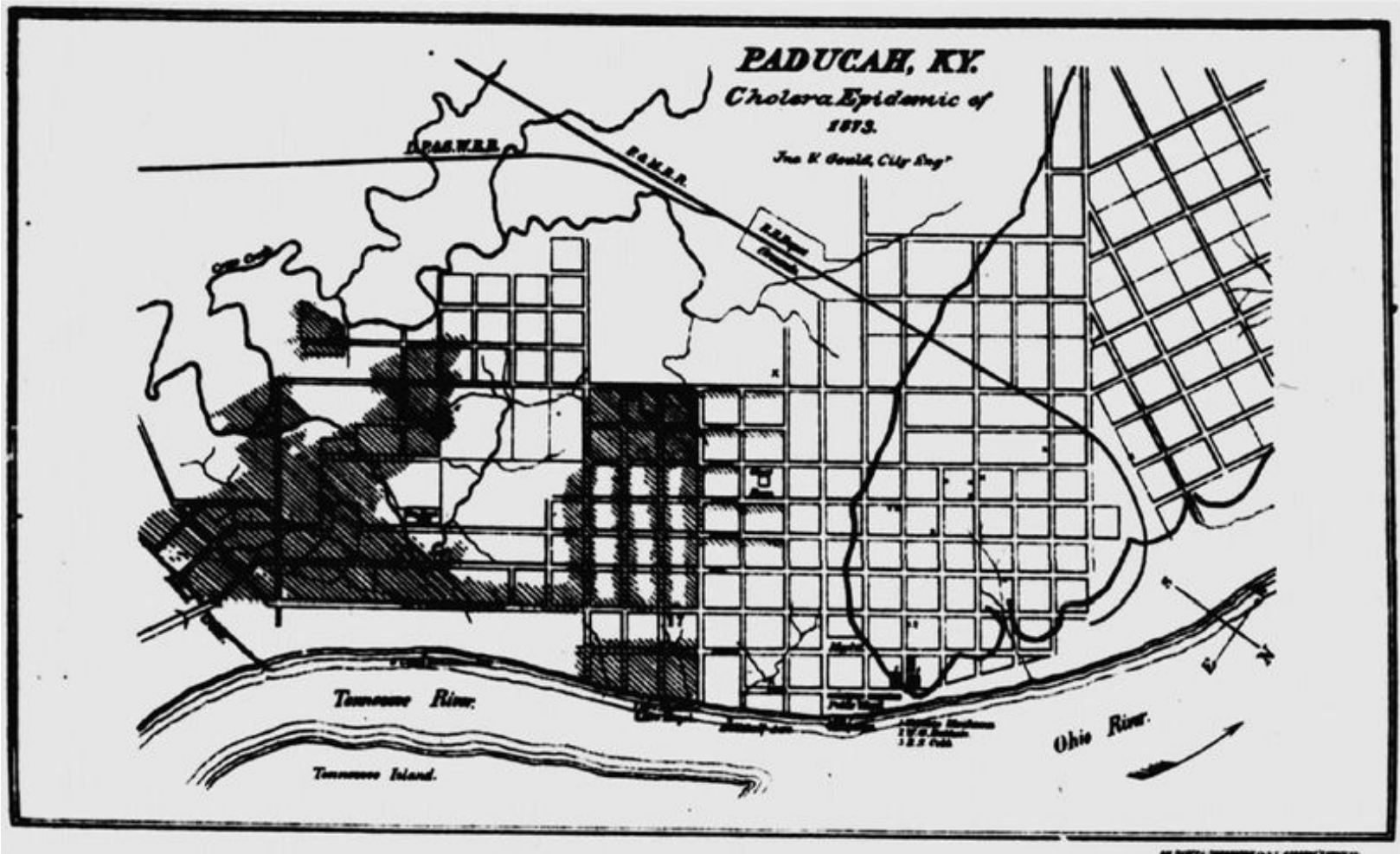

Figure 1. Cholera Maps from the Report to Congress on the Cholera Epidemic of 1873. Source: 43rd Congress of the United States House of Representatives, 1875. Report to Congress on the Cholera Epidemic of 1873 (Washington, DC: Government Printing Office,) p. 563 (top) p. 261 (bottom).

As different as these depictions of the city were, they eventually coalesced into coordinated action to control disease in the public realm as city officials were able to connect outbreaks to rotting waste, stagnant water, and crowded housing. The ultimate results of these investigations were comprehensive sewerage systems, paved streets, and improved building codes. The eradication of urban diseases was a key event in establishing the fields of public health and urban planning, professions that ultimately set the priorities and regulations to ensure the health and safety of urban denizens (Corburn, 2007; Melosi 2008).

\section{Drawing Ephemera: climate, airs and pulmonary disease at the turn of the $20^{\text {th }}$ century}

Until the Snow Map, determining the origins and spread of disease on a map was somewhat incidental to these in-depth descriptions of the urban environment. These narratives added dimension to medical cartography, which became medical geography, describing the underlying conditions in which illness or health could flourish. This practice was extensively used during the Civil War in order to survey appropriate areas for camps to keep soldiers away from miasmic airs and waters. After the Industrial Revolution, prevalent diseases were no longer thought to emanate from the ground, but rather to be airborne. The rise of pulmonary tuberculosis also spurred an interest in climatology. Much like the decidedly earthbound diseases of the Industrial 
Revolution played a key role in professionalizing the fields of engineering, urban planning, and public health, which shaped the ground, the onset of urban respiratory disease was an impetus to study prevalent winds and clean salubrious airs. The American Climatological Association was formed in 1883, and immediately and successfully lobbied for climatology to be taught in medical schools (Mitman, 2003). Many still viewed health as an outcome of the balance between body and nature, with the skin understood as an organ, but a porous one connected to all internal organs. As such, it would absorb environmental disturbances, such that radical changes in the weather could spur sickness (Valenčius, 2002). Climate was also understood as an entity influenced by interconnections between trees, soil, and water. It is then unsurprising that with the late $19^{\text {th }}$ century rise of the fields of landscape architecture and urban design, prominent figures such as Frederick Law Olmsted and Daniel Burnham advocated for widespread tree planting and large parks on the basis of public health (Hewitt and Szczygiel 2000). Olmsted had in fact been both a sanitary surveyor in the Civil War and a public health officer for the State of New York, experiences that would heavily influence his work and which are present in his extensive writings (Fisher 2010).

It was, however, difficult to depict how pulmonary disease spread, or how it was tied to specific aspects of the environment. Medical geographies functioned as both epidemiological explorations but also advertisements of rural relief for increasingly ill city dwellers. The findings were disseminated in publications, often including maps and personal accounts of how symptoms were mitigated once they arrived in the far-flung locations. Spread over a wider area, they lack the epidemiological preciseness of John Snow's maps, but provide a qualitative narrative of place, landscape, and nature. In his book Autumnal Catarrh (Hay Fever), published in 1876, Morrill Wyman, MD, wrote over 250 pages detailing the symptoms and possible causes of hay fever, and how the landscape of New Hampshire's White Mountains could mitigate the effects of the affliction, but in mapping the areas "safe from catarrh," simply indicates the entire northern area of the region as immune. Charles Denison, another physician and the author of Rocky Mountain Health Resorts: An Analytical Study of High Altitudes in Relation to the Arrest of Chronic Pulmonary Disease (1880), also did not locate areas or incubators of disease, but rather described the climatic conditions of the West in comparison to the more populous East Coast, documenting its humidity and cloudiness. The complexity and dynamism of Denison's map resembles the famous Fisk Map of the Mississippi River but preceded it by more than 60 years. The map was an experiment in depicting air and water in a graphic language that had previously only communicated topography. (Figure 2). Even Denison notes the difficulty in drawing conclusions from the map, noting “The reader is advised, before attempting to understand the Climatic Map, to read this accompanying explanation carefully, without which it might be liable to the criticism of being too crowded and complex" (Denison 1880, p. 26). However, the promise of clean high-altitude air and undeveloped pastures were enough. Writers such as Thoreau and Emerson further supported the idea that the sickly bodies of modern men and women would be restored if "returned" to nature (Marx, 2008). The diseases of concern in medical geographies of this era were then not so much defined by their origin, but rather the aesthetic of their curative landscapes, which were rural, 
mountainous, or otherwise conforming to a European pastoral ideal, as well as largely only available to the elite who had the time and resources to seek them out.

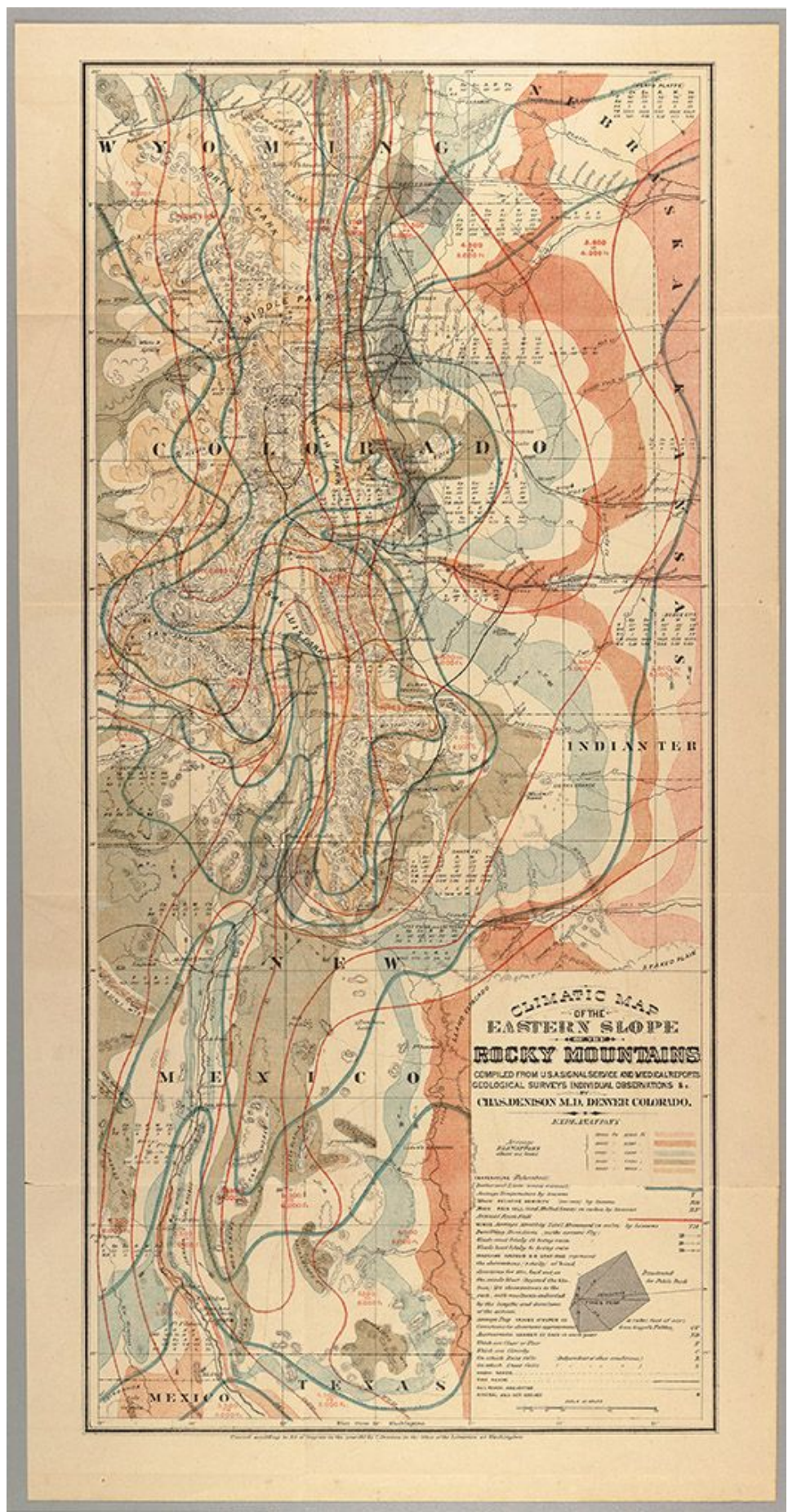

Figure 2. Charles Denison's Climatic Map of the Rockies.

Source: Denison, Charles. 1880. Rocky Mountain Health Resorts: An Analytical Study of High Altitudes in Relation to the Arrest of Chronic Pulmonary Disease. (Boston:

Houghton, Osgood and Company,) p. 26 


\section{Narrative voids and false metaphors: mapping "cancerous" urban blight and the AIDS epidemic}

In the early $20^{\text {th }}$ century, germ theory shifted medical thinking from environmental to etiological, and health from the scale of the population to the individual. In The New Public Health (1916) Hibbert Winslow Hill disparaged previous urban health programs, saying that these advocates had overlooked other origins of illness such as insects, hand and mouth contact, and food while “...dirty clothes, bad smells damp cellars, leaky plumbing, dust, foul air, rank vegetation, swamps, stagnant pools, certain soils, smoke, garbage, manure, dead animals, in fact everything physically, sensorially, esthetically, or psychically objectionable, were lumped together as 'unsanitary' without much distinction of 'source' or 'route,' and were regarded as a sort of general 'cause of disease' to be condemned wherever found, 'for fear of epidemics.” (Hill, 1977, 9) Hill warned that the profession had allowed for the broadest of generalizations, supported by miasma theory, to justify sweeping physical changes. More to the point he writes, "the great public-health fallacy of the nineteenth century consisted in the devotion of nearly all the effort to man's surroundings; of almost none at all to the man himself.” (Hill 1977, 9) Although figures such as Jacques May continued to advance the field of health geography in the mid-century, especially in thinking about disease ecologies, mapping was used more at the national and global level and depicted illnesses whose etiology was largely already known (Koch 2005, p. 236).

Disease mapping continued to be used to wield environmental control, but the illnesses were more metaphorical, leveraging the fear of the unknown and the graphic language of epidemics to eradicate the perceived origins. Many cities and towns undertook physical surveys for urban blight, several of them done block by block, property by property, similar to the Snow Map. A 1951 Architectural Forum advertising "slum surgery in St. Louis" shows "blighted" and "obsolete" districts beginning to encroach on the rest of the city grid, the former districts shaded as if to erase their existing characteristics (Shanken 2009, p. 70-74). In a 1968 article on urban renewal, new development in New Haven, Connecticut is shown in blood red, spatially clustered than slowly spreading out, emphasizing the cellular nature of urban landscape treatment (McConnell, 1968). These depictions are not unlike the amorphous shading earlier surveyors used to convey the spread of cholera along the Eastern Seaboard, a depiction of spreading illness that needed to be quarantined or excised through urban renewal lest it spread to more affluent outer neighborhoods. In doing so, the message conveyed was that blight was intractable unless causal origins were identified, while willfully neglecting to account for years of ingrained racism, policy, and disinvestment driving the crisis.

It is no surprise, then, that the image of cancer was often invoked in describing the malignancy of blight. As invoked in Sontag's Illness as Metaphor (1977), cancer was the bogeyman of the modern era, its etiology and treatment unknown, the first chronic disease to overtake infectious illnesses for causes of mortality. James W. Follin, commissioner of the Urban Renewal Administration, published the pamphlet "Slums and Blight...a disease of urban life," (1955) based on a lecture he gave at University of Michigan, in which he equated blight to population density and tuberculosis, using black clouds to show it radiating from the city center, the 
ostensible agent of contagion (Follin 1956). Even in smaller towns, blight was identified as a convenient correlating factor for physiological and social disorder. A blight survey for the town of Clinton, North Carolina undertaken in 1965 counts each blighted property alongside cases of tuberculosis, venereal disease, juvenile delinquency, and without further distinction, cases of public assistance. Health historians Susser and Susser (1996) identified the latter half of $20^{\text {th }}$ century epidemiology as being dominated by a "black box" paradigm which linked multiple exposures to outcomes without knowing all intervening (i.e., genetic) factors. Chronic disease was as unknowable to many researchers as infectious disease had been to researchers of the Industrial Revolution era. In the absence of more straightforward pathways, once again they sought any and all explanations. What did emerge in this time period was the effectiveness of lifestyle interventions (i.e., smoking, diet) and reducing environmental exposures (Susser and Susser 1996). These risk factors were still largely thought to be the responsibility of the individual, though, a holdover from the biomedical model of health that emerged after germ theory. In the case of blight, urban planners played amateur physicians by identifying correlators, but by conflating physical ruin, illness, and poverty--data that was easily obtained and located-- these surveys communicated that all three were connected, and constituted a moral failing on the part of its victims. Blight mapping in turn played a key part in providing evidence for clearing neighborhoods primarily inhabited by African-Americans for urban renewal. The ensuing mass displacement was in turn the cause of equally disastrous health effects (Lopez 2009).

The AIDS crisis of the 1980's invoked a similar fear of the unknown, but early medical cartographers also encouraged harmful associations by simultaneously de-spatializing its reach and concentrating too narrowly on density and other "urban" characteristics in assumptions about its spread. Controversially, many tried to predict its diffusion by the presence of gay men, behavior, or population density. Without understanding its cause, in and of itself a result of the Reagan administration's refusal to recognize and consequently fund the disease, the popular public conception, aided by visual and written health narratives was that it was a disease born of the supposed worst conditions of the city - "deviant” sexual behavior, drug use, and neglect. As in their earlier studies of the "contagion" of blight, Wallace and Wallace, et al. (1995) attempted to describe the spatial spread of the illness and recalled the dilapidated physical conditions of the city as incubators, if not the actual cause of the disease. Rather, abandoned neighborhoods that made "refuge" for the disease indicated the fragmentation of social policies and city services (Wallace, and Wallace et al. 1995). Most famously, though, Peter Gould's 1993 AIDS map predicted spread based on population density of its outbreaks, describing a "step-jump" pattern of disease that would place hotspots of future outbreaks in other urban areas but with suburban than rural areas as less affected but no less collateral damage. His diffusion maps of the AIDS crisis as a national epidemic originating in cities were graphically effective and are often (and uncritically) held up as a watershed moment for the field (Koch 2011). (Figure 3) Less widely known are his more experimental maps which again collapse the epidemic as one belonging to more populous areas, showing Ohio's major cities (Cleveland, Cincinnati, and Columbus) clustered together with disease vectors connecting them, and other equally sized dots representing suburban and rural communities hovering at the margins, precariously safe from its spread 
for the moment. Roderick Wallace and Gould would come together to again warn about the spread of AIDS to adjacent communities based on "commuter intensity," centering Manhattan and predicting its spread to the suburbs, in particular highlighting the possible danger of a third tier of infection for heterosexual women, after male homosexuals and intravenous drug users (Gould and Wallace 1994). Gould's work was viewed as a bellwether and voice of authority, but reconsiderations of the work note that as much as it tried to present a politically neutral, rationally spatio-temporal view of the epidemic, its conclusions were limited by wider cultural biases and misunderstandings of the disease. The diffusion model implicitly suggested that urban gay men were merely vectors of the disease, divorcing the disease from social conditions and thus its possible prevention. Brown (1995) argued that the way the AIDS crisis was mapped effectively distanced researchers from the social spaces of gay men in the 1980's, that they were “represented and simultaneously erased." He also noted that without a real ethnography of how gay men were interacting with each other in their own spaces, and in many cases trying to actively prevent its spread, the virus was simply conflated with its victims, made faceless in its depiction. However, Gould himself gets little credit for recognizing this ever-present problem in health-related spatial analysis, and, at the end of an article on predictive mapping, highlighted that by only taking time and space into account in any graphic depiction of disease, "In the AIDS epidemic, as in other realms of human inquiry, this ignorance has cost us dearly in understanding, in our ability to intervene, and in our ability to plan. Perhaps it is time to bring the geographic back into human scientific thought.”

(Gould et al. 1991 p. 90).

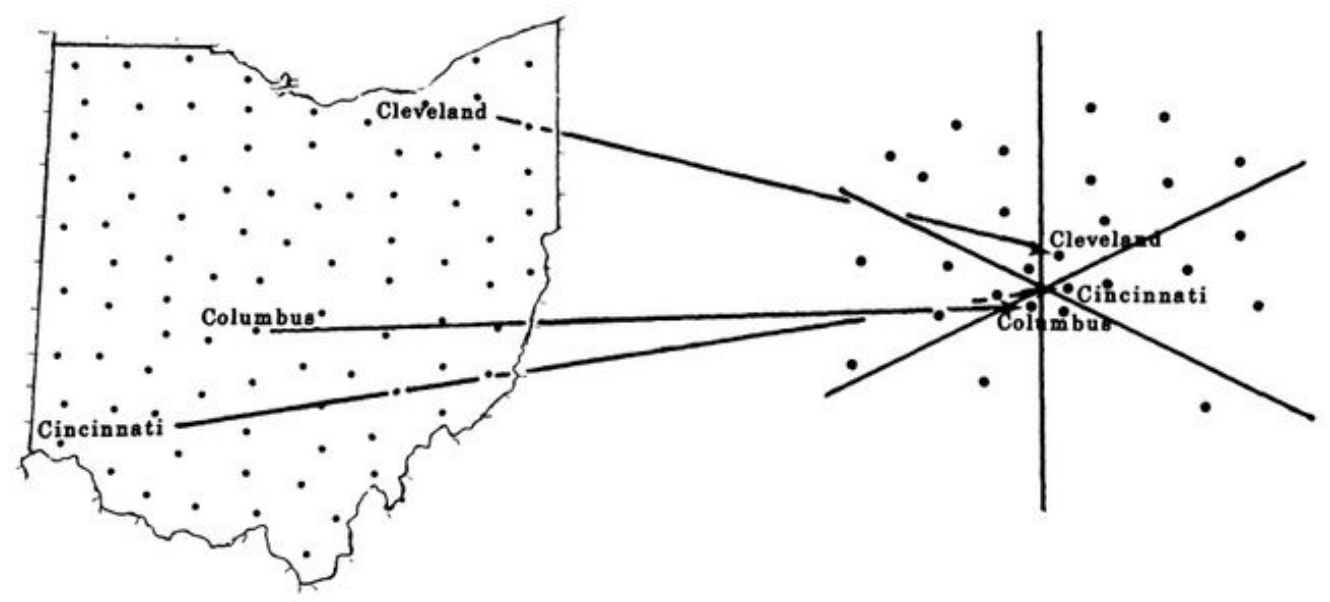



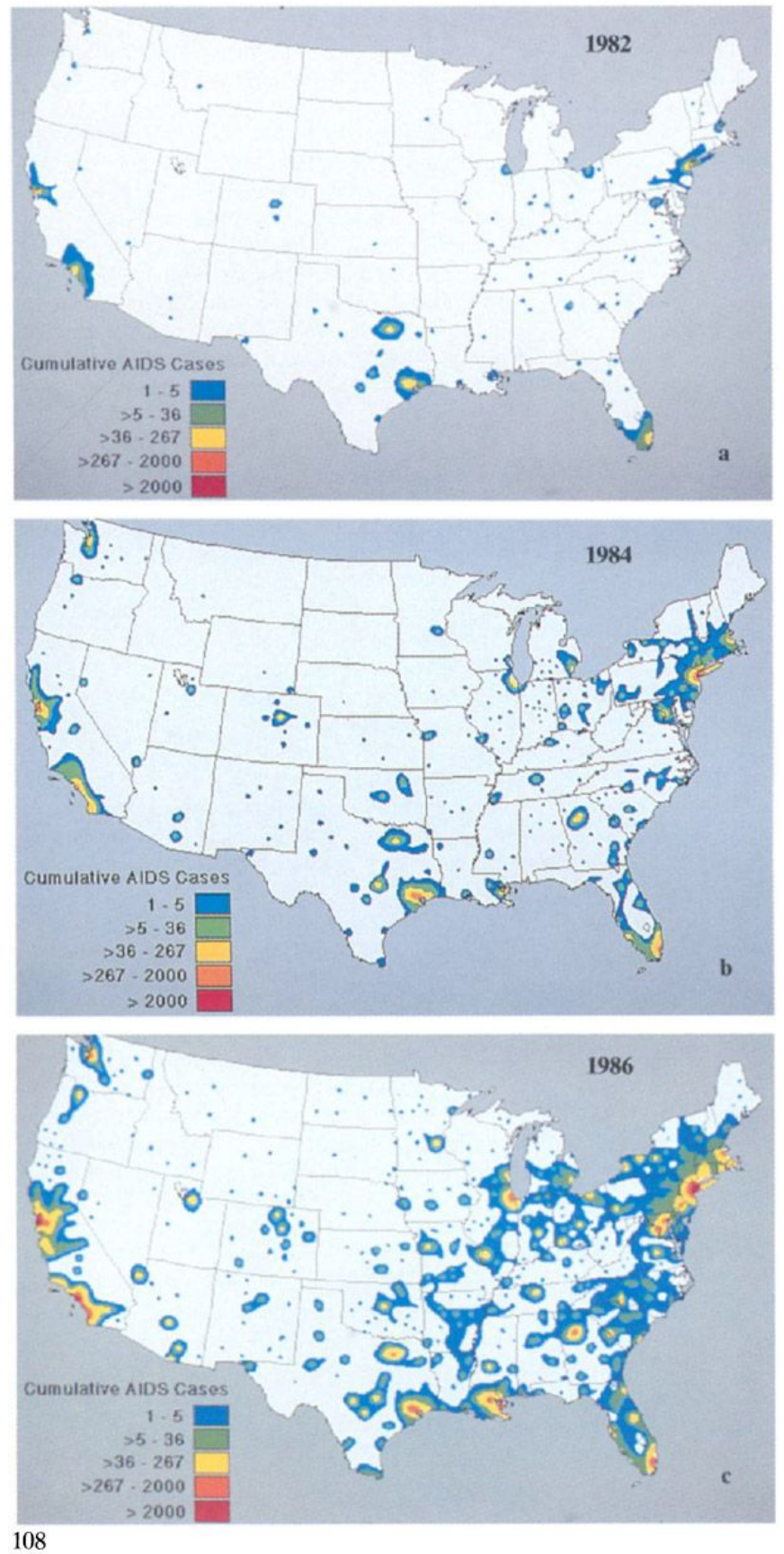

Figure 3. Peter Gould's step-jump and diffusion maps of the AIDS epidemics. Gould, Peter., Joseph Kabel, et al, . 1991. "AIDS: Predicting the next Map. (Special Issue: AIDS Modeling)." Interfaces 21, no. 3: 80-92, p. 90 (top).

Gould, Peter and Rodrick Wallace, 1994. "Spatial Structures and Scientific Paradoxes in the Aids Pandemic." Geografiska Annaler: Series B, Human Geography 76, no. 2 : 105-16, p. 108 (bottom). 


\section{Uncertain space: the black box of environment and $21^{\text {st }}$ century disease}

Empirical research on how the landscape, design of towns, and form of our workplaces and homes makes us sicker or healthier has exploded in the past 20 years. A report in the American Journal of Public Health by Jackson, Dannenberg, and Frumkin noted that between 1993 and 2003, a PubMed search using the terms “health” and "built environment” yielded 39 results. Between 2003 and 2013, it yielded 675 (Jackson, Dannenberg, and Frumkin 2013). In late 2019, there were more than 2,400 results. The evidence for how place effects health has potential to inform future policy, evidenced by a 2016 address and article from Karen DeSalvo, then-interim secretary of the U.S. Department of Health and Human Services, who noted that public health had entered a new era, where "one's zip code is a better indicator of health than genetic code" (Desalvo et al 2016). This connection has also permeated the popular media, where there is no shortage of competing lists of the "healthiest" places to live or geographically coded "Well-Being Indexes," ranging from sources as disparate as Forbes magazine and The Travel Channel to the health nonprofit Robert Wood Johnson Foundation. The online publication CityLab has written several articles declaring which places are America's Healthiest Metros, although the criteria has changed year to year from simply where the lowest rates of smoking or obesity are, to repurposing the American Fitness Index (Florida 2012, Florida 2016). The Blue Zones Project, a private wellness consultancy, has studied behavioral and physical aspects of place in the five communities around the world with the highest rate of centenarians and is currently working with several local governments to replicate those conditions in their own towns. There is little agreement on what constitutes a "healthy” place, though. We are left with simultaneously too much data on hand, and too little information about what it all means. Everything seems to play a part in our health outcomes, but without a trajectory of how to move forward.

The rules of epidemics have also changed significantly. Chronic diseases predominate both the physical and metaphorical landscape but are noncommunicable, persistent, and most crucially, without a single microbial cause. Important public health challenges of the $21^{\text {st }}$ century - violence, obesity, opioid use, among others - are deeply tied to the environment but also to social and economic determinants. Much like acute diseases, they spread, and therefore invoke fear in those living in adjacent communities, but their pattern is less known. The nature of disease itself has changed, with longer temporal scales and multiple contributors that range from genetic to external. We are still in the era of Susser and Susser's "black box" epidemiology, and health mapping has again become a form through which investigators attempt to uncover spatial epidemiology, aided by the increasing proliferation of data. For all the availability of data, though, the medium is limited by time, space, and units. In an unintended irony to DeSalvo's otherwise insightful statement of how public health has changed over the past 150 years, the use of zip codes in dictating the contours of place and health is chief among the confounders in delineating the relationship. 
The ways we stratify the landscape to represent "healthy” or "unhealthy” places, most often census tracts, zip codes, or other administrative boundaries, have no real relationship to the gradients of streets, housing, or other characteristics cited in these studies. This is due to the way health data is collected, which is often by selfreport survey or hospital admission data and aggregated for privacy reasons. The privacy principle is nonnegotiable when it comes to spatial study. However, this both complicates efforts to determine the strength of the relationship between development and health outcomes, and results in the characterization of large swaths of neighborhoods, cities, or even states themselves as detrimental or desirable without the required nuance. There is very little literature on how to properly disaggregate health and space in tandem, although methods of spatial interpolation could be used to better gauge their relationship (Lam 2012). Research and multilevel models of correlation have added empirical evidence that dimensions of the urban landscape such as parks, trees, land use, and building form-- long thought anecdotally to influence health outcomes-- can impact them. The most robust studies are often done at the scale of neighborhoods or even smaller, but when it comes to mapping these effects on a larger scale, conclusions often suffer from what Kwan (2012) termed the "uncertain geographic context problem," an extrapolation of an issue earlier identified by Openshaw (1984) as the "modifiable areal unit problem," where the units used do not necessarily match up with the phenomena studied. Besides the ecological fallacy potential of inferring large scale context on individual behaviors, it also perhaps places an undue importance on residential neighborhood effect, which has been well studied and has been key to understanding the effect of economic and social segregation on health outcomes (Diez Roux 2001; Sampson 2003). but also presupposes in its use of home zip codes that environmental exposure is limited to place of residence, without meaningfully integrating commutes, places of work, and social spaces. Nor does it adequately take into account the very strong possibility that people may respond differently to the same environmental factors, or that built environments change over time (Kwan 2018). This does not discount the nuanced dimensions of place that have advanced public health and geography research in the past 50 years, especially when it comes to the environmental justice field. Even there, however, the spatial visualization of hazards are more than often cross-sectional and misaligned in scale between location and spread of hazards, populations, and health outcomes (Buzzelli 2007). While public health practice has largely shifted to a socioecological model of disease and intervention, our modes of mapping remain largely etiological.

\section{Obscuring etiology: the unruliness of the obesity and the environment}

The gaps between social-economic context, chronic disease epidemiology, and spatial visualization of the built environment can swiftly become problematic, as seen in the case of obesity and determining neighborhood “walkability.” Most studies found in Jackson, Dannenberg, and Frumkin’s 2013 AJPH review concentrated on the relationship between obesity, physical activity, and built environment. Obesity, like cancer and tuberculosis before it, is the intractable and unknowable disease of our time. It has no real treatment, and its most effective interventions are preventative measures, making the epidemic even more difficult to combat. In 2016, the CDC reported that 39.8\% (93.3 million) of all U.S. adults were obese, and 18.5\% of children ages 2-19. The agency 
speculated that the annual medical cost of obesity was \$147 billion (Centers for Disease Control 2017). Obesity's apparent relationship to auto-oriented sprawl - in of itself an unruly environment, i.e., one that does not conform to best planning practices or any discernable patterns of expansion - is now a common cause that reunited the planning, design, and public health fields. While there have been many, many studies attempting to comprehensively index what variables make a neighborhood walkable, with observed characteristics ranging from 10 to over 200, the most visible measurement by far is by Walk Score, a private tech company which has generated publicly available, online choropleth maps and ratings between 0-100 for major American cities (Walkscore.com, Forsyth, 2015). For all the research done on this topic, Walk Score heavily weighted its algorithm based on one factor - "amenities” (Primarily retail: grocery stores, coffee shops, restaurants, bars, movie theaters, schools, parks, libraries, book stores, fitness centers, drug stores, hardware stores, clothing/music) within a 30 minute walk. They also measured the most commonly examined, and easily attainable objective features in walkability research, chiefly population density, block length, and density of intersections.

Walk Score's proprietary algorithm proved popular enough that it was bought by real estate company Redfin six years after its founding, and it has been utilized in many public health studies, often as a proxy by those unfamiliar with the nuances of planning and design (Towne et al. 2016). That an "objective” measure of walkability exists has been a precept of many studies, despite the fact that people experience environments differently (Kwan 2018). That assertion has rarely been tested across lines of race and class; in a notable study Adkins, et al. (2019) finding that Hispanic populations valued social dimensions of public space (ie, safety, maintenance) in terms of walkability, while White populations favored physical amenities. Another bellwether of interest in health data, particularly geolocated physical activity data, has been evidenced by Google's purchase of activity tracker company Fitbit (Copeland and Thomas 2019). While the true motives for the latter have not yet been revealed, it is probably safe to say that Google's interest in urban development (as evidenced by its offshoot Sidewalk Labs), health, and optimization points to a use of this tool that might potentially transform cities, but that risks being divorced from decades of research on geographic context others have built up. Walkability measurements often overlook social and equity of neighborhoods in favor of physical features, although these are key to other foundations of health such as social cohesion and access to jobs and services.

It also remains that the actual epidemiology of obesity is somewhat inconclusive, although several studies have confirmed it to be tied to poor socioeconomic status and several physical factors, from food availability to recreational and transportation infrastructure (Hruby and Frank Hu 2015). Much like AIDS maps of the 1980's and early 1990's, obesity is normally depicted on a national level at the scale of states, which portrays its "contagion" as federal issue rather than one that should be addressed on a place-based level, and suggests that obesity is a problem confined to the rural South and Midwest, far away from elite coastal cities (Hamblin 2013). Its distance in effect allows it to be ignored or even disparaged as a real health crisis. Mapping as a medium in and of itself is still limited to single factor overlays, bound by these administrative frames. Cities like Chicago and Los Angeles have published detailed health atlases, attempting to find the intersections 
among demographics, education, and infrastructure, but often each layer of data is isolated and otherwise without context, confined to the clear boundaries of zip codes and tracts. And if maps are meant to be a depiction of the physical environment, the descriptions of place are curiously absent. The otherwise clearly designed and comprehensive Plan for Healthy Los Angeles describes the built environment as "land use" and limits it to a self-designed "walkability index," based mainly on population density, intersection density, and land use mix, and access to parks (Los Angeles Department of City Planning 2013). (Figure 4) The Chicago Health Atlas documents a wide ranging number of health outcomes, ranging from mental health, maternal health, violence, preventative care, and access to health facilities, but its physical factors are largely limited to climate, housing, and active transportation. The last factor is not a measure of the environment itself but rather a self-report factor of residents walking, biking, or taking public transportation to work (City Tech Collaborative and the Chicago Department of Public Health 2018). Many of these health outcomes are driven primarily by economic factors, and while these atlases do effectively communicate how health inequities and income inequality are inextricably tied, they do not yet unlock insights into how the built environment plays a part. 


\section{Walkability Index}

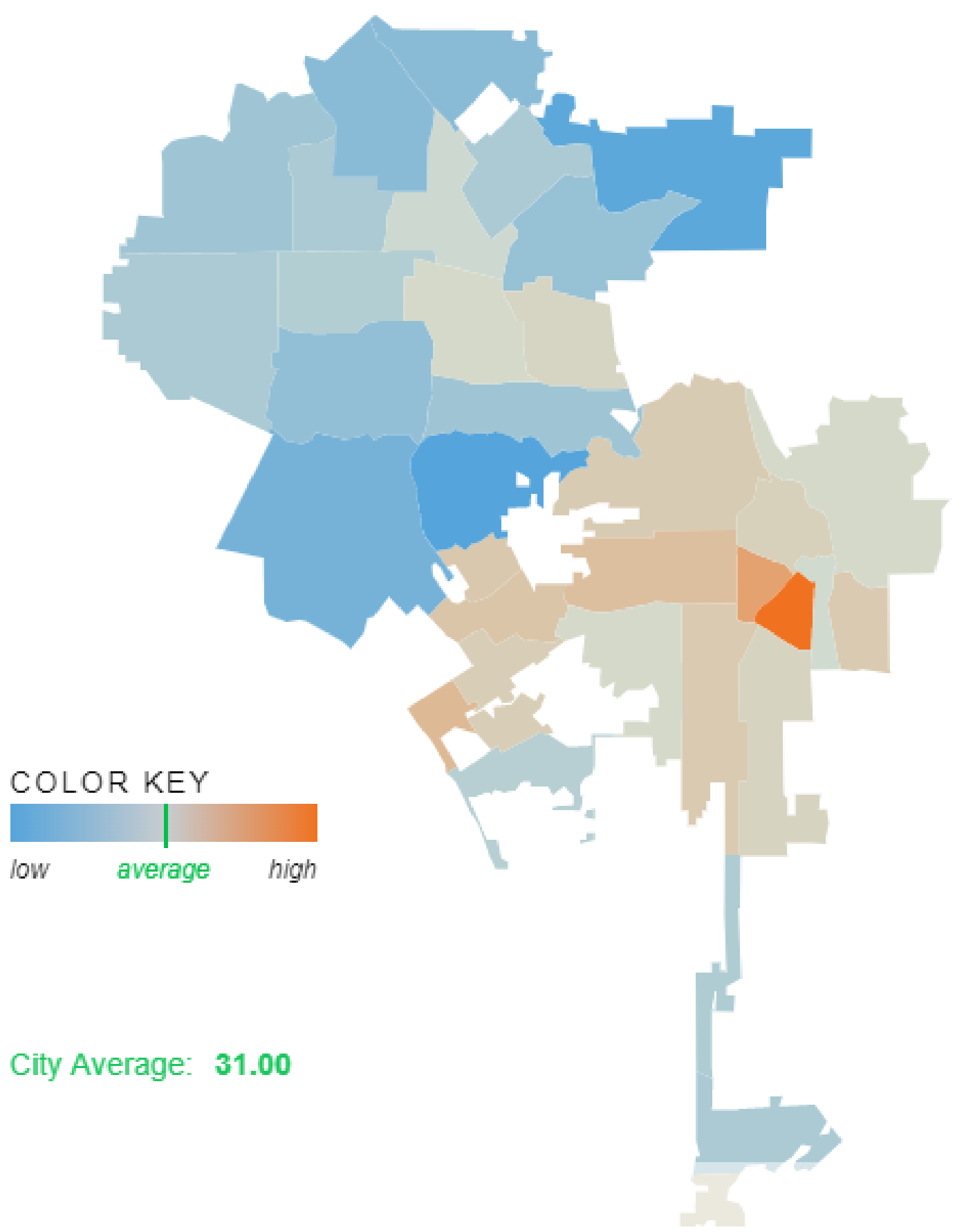




\section{Prevalence of Childhood Obesity}

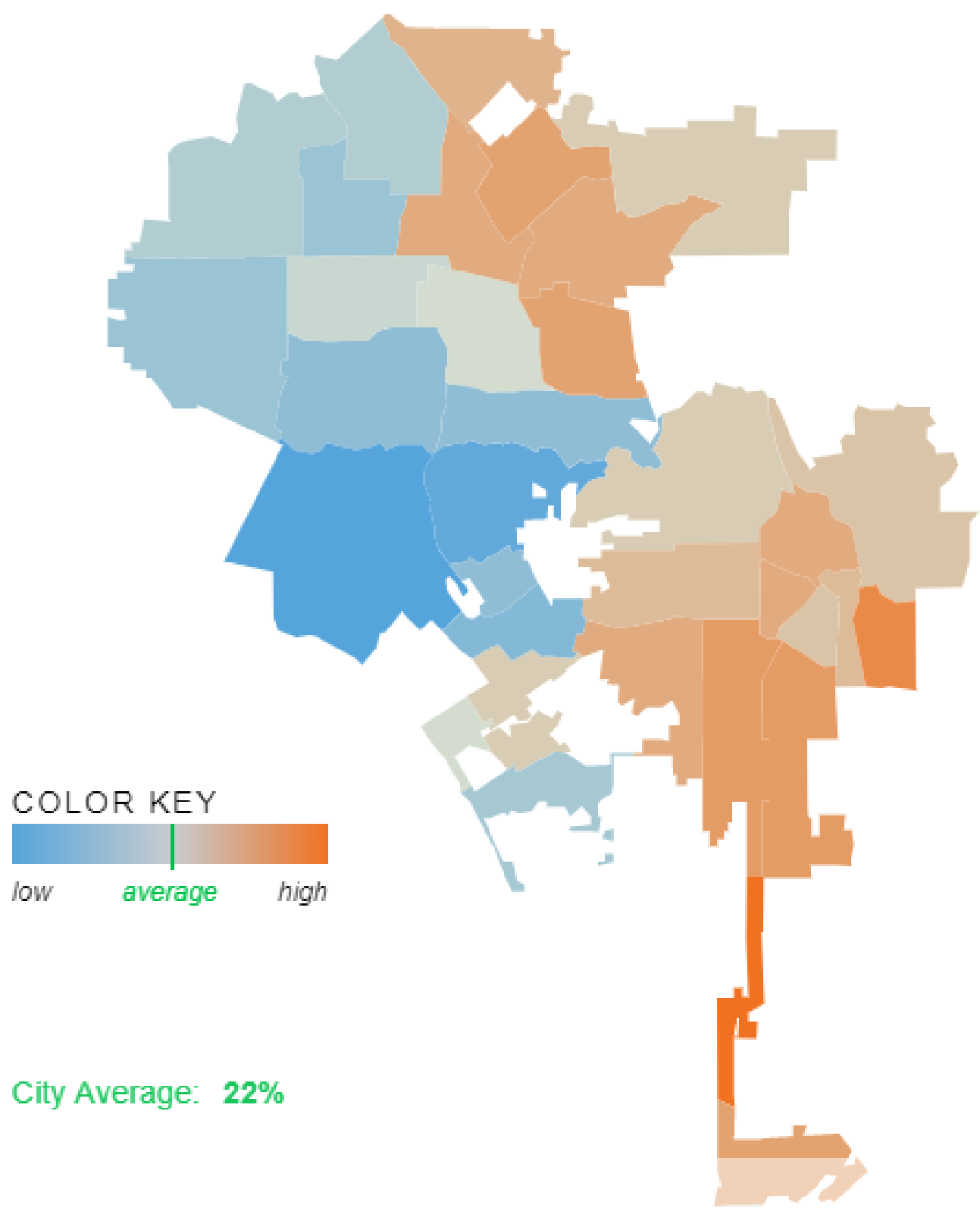

Figure 4. PLAN for Healthy Los Angeles maps (2012).

Source: Los Angeles Department of City Planning. 2013. "PLAN for a Healthy Los Angeles: Interactive Map", http://healthyplan.la/interactive/cityl.

The increased interest in this relationship across disciplines and in the general public is certainly a positive, but a lack of common language or understanding of place often leads to spatial investigations into health that default to data that is available and more immediately understandable, rather than discovered and transformed. 
Consider the inordinate amount of attention given to "density” in the literature on active travel, obesity, and built environment. Density is (at first glance) easily quantifiable and available as a metric. It can be conveyed through seductive graphics. It connects a range of scales from on-the-ground experience to zoning. Its use as an indicator of health is also a holdover from our age of infectious disease, when crowded tenements and person to person contact did indeed ignite epidemics. Its use as a proxy for "urban" environments could also be seen in Gould's AIDS maps in the 1980's. However, the factors in a density calculation can be drawn from population, housing units, or building height - each with different implications (Churchman 1999). It alone is not enough to create or even form the foundation for healthier environments, especially when the space in between is not considered in tandem. Nor can it be separated from its design or social contexts.

Those in health geography understand this nuance and have debated the difference between medical geography and the geography of health (Kearns 1993). The former is traditional spatial disease tracking, the latter more concerned with webbed relationships between health, place, and health-related services and informed by social theory (Rosenberg 1998). Geography is not geometry, but increasingly user-friendly mapping software and the aforementioned availability of data collectively lets anyone create their own health maps, or rapidly compile spatial information that, though not proven to be correlated with urban disease, when presented alongside these cases appears to imply the relationship. This should not be seen as wholly negative, however, since open use data and mapping as communication could have great implications for individuals and communities to empower themselves where government entities have otherwise failed, especially in the arena of environmental justice (Maclachlan et al., 2007).

\section{Blurring the lines of place and health: re-considering health mapping in the $21^{\text {st }}$ century}

What is the result when spatial data we use to try and determine the relationship of the environment to health is misaligned with the contours of urban landscape? On a pragmatic level, funding decisions and policy are also often made along the same invisible lines of health data. If targeted to improve urban development, the desired effects may not be seen, or in the worst-case scenario, force out vulnerable populations. "Healthier" neighborhoods have a history of commodification throughout American history, although the form of those places have changed along with each era's illness. From suburbs built to escape the ill effects of the city to today's walkable neighborhoods, there is often a premium placed on health access (Moser 2013; Leinberger and Lynch 2016). This is further complicated by the fact that study on health and the built environment is stratified by socioeconomic status, figured to be too much of a confounder on outcomes to include in modeling (Adkins et al., 2017). The scientific impulse to anonymize the admittedly messy reality of landscape instead results in conclusions that are offered as universal solutions, when the priorities and needs of public health are instead uniquely place-based. Obesity, while not necessarily a signifier of bad health in of itself, appears to many to be an outward signifier of choices from what we eat to where we live, no matter how much those "choices" are dictated by the environment. The oft-cited 2008 economics paper "Fat City: Questioning the 
relationship between urban sprawl and obesity," which followed people that had moved from sprawling to "less sprawling” neighborhoods and found no difference in weight after a year concluded, "People who are more likely to be obese (e.g., because they do not like to walk) are also more likely to move to sprawling neighborhoods (e.g., because they can more easily move around by car)...It follows immediately from our results that recent calls to redesign cities in order to combat the rise in obesity are misguided.” (Eid et al 2008) Overlooked by this study and many others is that healthy environments become more desirable, more expensive, and subject to commodification. Five years after the rating system's inception, a study found that neighborhoods in Seattle rated most walkable by Walkscore also had higher median monthly rents. Truly walkable neighborhoods are becoming increasingly out of reach to those most vulnerable to disease and in need of access to resources.

The gaps between maps and qualitative description are subject to fall victim to Americans' steadfast attachment to "healthism.” A term coined by political economist Robert Crawford in 1980 places all health outcomes as the responsibility of the individual and its achievement as a sign of being a good citizen, or even a "badge of honor." Conversely, those suffering from bad health are perceived as a burden on society (Crawford 1980). His conclusion is hardly a far cry from late $19^{\text {th }}$ century concerns that the poor could not be taught sanitary habits, or that immigrants preferred to live in crowded tenements. In a critique of AIDS geographies, Brown noted the failure of medical mapping to reflect place, which instead has the unintended effect of reducing certain populations to a "risk group,” or "bodies as vectors” effectively decoupling these environmentally based diseases from the environment and instead stigmatizing the afflicted (Brown 1995). Health in the United States is often seen as a series of choices. Although Rene Dubos posited that health outcomes are a result of the "success or failure to adaptively respond to environmental challenges," (Dubos 1965, p. xvii.) we have altered our environment to the extent that some have not been able to adapt. The adaptation is not only physical, but economic as well. The increasing fault lines between health equity only confirm that some can buy their way to better outcomes, whereas others are trapped in places that attenuate risk. While the state has increasingly been absolved of its responsibility to ensure well-being, capitalism has rushed in to take its place, commodifying "wellness" in its stead, which is a recurring pattern that now extends to our urban landscape.

Current attempts to link social, economic, and health data to the physical environment, especially by local entities, are admirable, and the interest in such factors by institutions as influential as the Centers for Disease Control, whose 500 Cities Initiatives is attempting to collect spatial health data at a much more granular level than ever before, should be energizing to all of us invested in the topic. But if the desired outcome is a healthier, and most importantly, equitable environment, the architecture, urban planning, and public health fields must be more proactive about setting a research agenda that does not simply reiterate the benefits of walkable streets and parks. What if we used mapping as a tool to critique the practice itself and how it has seeded present-day health inequities? A University of California study found recurring patterns statewide of childhood and adult asthma in historically redlined communities, showing how social and economic policies 
can have physiological effects, even generations removed (Manke 2019). This can also not be separated from the fact that supposedly lesser health and mortality were leveraged in many housing covenants as justification to keep minorities and immigrants out of white neighborhoods, quarantining them populations in a cycle of illness. (Shah 2001; Lubar 1986).

Beyond integrating policy and social narratives into mapping, it is also time to start seeking more methods in how this data is collected and represented. As it is, GIS is largely underutilized by the health field (Maclachlan, et al., 2007) which likely contributes to the co-option of health mapping by others, often private companies. Sensors, mobile phone technology, open data platforms and ever more sophisticated tools offered by geospatial information systems (GIS) present an opportunity to both collect real-time data and show longitudinal effects of the built environment. Collaborations with architects and landscape architects to delineate more nuanced gradients of built environment change could help break out of predetermined administrative boundaries. New visualizations are needed to spur conversation and better understand how the built environment interacts with social and economic environments. If the interest from companies like Google and Amazon indicates that the data sought to shape future healthcare is in individual biometrics, how do we ensure these contexts are not overlooked? These issues are key not only to better communicate the impacts of the environment on health outcomes but can lead to more pointed research questions to advance understanding of that relationship in the first place.

\section{Conclusion}

Cartographers, scholars, and the healthcare sector alike have largely de-emphasized the effect of external environments on our own bodies in the latter half of the $20^{\text {th }}$ century. Even though spatial data has become more individualized and more granular, many miss the larger picture of how the abundance of data intersects, and may instead obscure the answers we seek.

As I write this in March of 2020, much of the world is preoccupied with the spread of the novel coronavirus. The panic induced by COVID-19 stems precisely from its uncertainty, namely its vectors and physical properties of its incubating environments. Most people have pointed to the Johns Hopkins University Center for Systems Science and Engineering map as the best source of tracking outbreaks, and indeed it is a reliable aggregator of multiple international sources in a time of conflicting and confusing information (Johns Hopkins University and Medicine, 2020). In real-time, red bubbles grow with reported cases over a dark gray world map, with numbers and graphs soberly ticking upward on the side. While some may find it reassuring in its unimpeachability, it is also encapsulates what we do not know. Unlike past epidemics discussed here, it does not appear to discriminate between city or suburb. These values are likely underreported by government agencies due to lack of testing, making the data itself an unreliable indicator. Even so, the reliance on circles and borders communicate a containment that is not reflective of the current situation. This is not the fault of the cartographers and researchers, they are simply following over 200 years of traditional spatial representation as a first step in understanding this disease in space. The key to understanding its epidemiology is likely in our 
myriad scales of social connections, down to the scale of individual households and up to the paths and intersections of globalized travel and trade. A dedicated team of network scientists is currently examining these relationships, a massive computing task that has required free cloud space from Google to accomplish (Benedict 2020). The extreme social distancing measures that states, counties, and cities have put into place attempt to freeze this literal Gordian knot until they can isolate these lines of contact. With any hope, by the time you read this, we will know more about the nature of the virus - its spread, the physical conditions under which it flourishes or dies, and the impact of policy responses and behavior change.

If we can relate these issues to each other in space, it may indeed prove to be the Snow Map for the $21^{\text {st }}$ century: the key that unlocks our understanding of how we embody our environment not just for infectious pandemics but for chronic illnesses as well. To get there will require us to in part reject the "reality" of how maps depict our communities and instead accept a degree of messiness and uncertainty as we widen our scope to include historical, social, and environmental histories and find how they do or do not align with the urban landscape. We should view these not as ephemera but rather as systems that are as spatially rooted as the hard infrastructure used to improve urban health over a century ago. We must map them with an explicit focus on equity. We must find ways to disaggregate health information in a way that still protects privacy, especially of those that are most vulnerable, and synthesize built environment information in a way that makes sense for considered action in the field. The problem of accurately representing the complexity of our present-day built environment and chronic disease may be unsolvable one, but to even begin to answer the question requires an acceptance that the suite of methods and data we currently default to are lines far more blurred than they appear.

\section{References}

43rd Congress of the United States House of Representatives, 1875. Report to Congress on the Cholera Epidemic of 1873 (Washington, DC: Government Printing Office,).

Adkins, Arlie et al., 2017. "Contextualizing Walkability: Do Relationships Between Built Environments and Walking Vary by Socioeconomic Context?," Journal of the American Planning Association 83, no. 3, https://doi.org/10.1080/01944363.2017.1322527.

Adkins, Arlie, Gabriela Barillas-Longoria, Deyanira Nevárez Martínez, and Maia Ingram. 2019. "Differences in Social and Physical Dimensions of Perceived Walkability in Mexican American and Non-Hispanic White Walking Environments in Tucson, Arizona." Journal of Transport \& Health 14: 100585.

Benedict, Carey. 2020. "Mapping the Social Network of Coronavirus,” The New York Times, March 13, https://www.nytimes.com/2020/03/13/science/coronavirus-social-networks-data.html.

Brown, Michael. 1995. "Ironies of Distance: An Ongoing Critique of the Geographies of AIDS." Environment and Planning D: Society and Space 13, no. 2: 159-83.167 
Buzzelli, Michael. 2007. "Bourdieu Does Environmental Justice? Probing the Linkages between Population Health and Air Pollution Epidemiology." Health and Place 13, no. 1: 3-13.

Centers for Disease Control. 2017. "Overweight and Obesity,", https://www.cdc.gov/obesity/index.html.

Churchman, Azra, 1999. "Disentangling the Concept of Density." Journal of Planning Literature 13, no. 4: 389411.

Citizens' Association and Council Of Hygiene And Public Health Association Of New York. 1865. Report Of The Council Of Hygiene And Public Health Of The Citizens' Association Of New York Upon The Sanitary Condition Of The City (New York: New York: D. Appleton and Co.,), p. 196.

City Tech Collaborative and the Chicago Department of Public Health. 2018. "Chicago Health Atlas: Indicators,”, https://www.chicagohealthatlas.org/indicators. Accessed July 2019.

Copeland, Rob and Patrick Thomas, 2019. “Google Bulks Up In Devices With Deal For Fitbit,” Wall Street Journal, November 2, A1.

Corburn, Jason. 2007. "Reconnecting with Our Roots: American Urban Planning and Public Health in the Twenty-first Century," Urban Affairs Review 42, no. 5. https://doi.org/10.1177/1078087406296390

Crawford, Robert. 1980. "Healthism and the Medicalization of Everyday Life." International Journal of Health Services 10, no. 3: 365-88.

Denison, Charles. 1880. Rocky Mountain Health Resorts: An Analytical Study of High Altitudes in Relation to the Arrest of Chronic Pulmonary Disease. (Boston: Houghton, Osgood and Company,) p. 26

Desalvo, Karen B. et al., 2016. "Public Health 3.0: Time for an Upgrade," American Journal of Public Health 106, no. 4, https://doi.org/10.2105/AJPH.2016.303063.

Diez Roux, Ana. 2001. "Investigating Neighborhood and Area Effects on Health." American Journal of Public Health 91, no. 11: 1783-789;

Dubos, René J., 1965. Man Adapting. Mrs. Hepsa Ely Silliman Memorial Lectures. (New Haven: Yale University Press) p. xvii.

Eid, Jean et al. 2008. "Fat city: Questioning the relationship between urban sprawl and obesity,".Journal of Urban Economics 63, no. 2.

Fisher, Thomas. 2010. "Frederick Law Olmsted and the Campaign for Public Health." Places Journal. September 11, 2013.http://places.designobserver.com/feature/frederick-law-olmsted-and-the-campaign-forpublic-health/15619/. 
Florida, Richard. 2012. “America’s Healthiest Metros,” Citylab, January 4, https://www.citylab.com/design/2012/01/healthiest-metros/367/

Florida, Richard. 2016. “America’s Great Fitness Divide,” Citylab, JAN 11, https://www.citylab.com/equity/2016/01/americas-great-fitness-divide/414558/

Follin, James W. 1956. Slums and blight --a disease of urban life (Washington, D.C.: Urban Renewal Administration, Housing and Home Finance Agency)

Forsyth, Ann. "What Is a Walkable Place? The Walkability Debate in Urban Design." Urban Design International 20, no. 4 (2015): 274-92.

Gould, Peter and Rodrick Wallace, 1994. "Spatial Structures and Scientific Paradoxes in the Aids Pandemic." Geografiska Annaler: Series B, Human Geography 76, no. 2 : 105-16.

Gould, Peter., Joseph Kabel, et al, . 1991. "AIDS: Predicting the next Map. (Special Issue: AIDS Modeling)." Interfaces 21, no. 3: 80-92, p. 90

Hamblin, James. 2013. “Look How Quickly the U.S. Got Fat (1985-2010 Animated Map),” The Atlantic, April 11,; https://www.theatlantic.com/health/archive/2013/04/look-how-quickly-the-us-got-fat-1985-2010-animatedmap/274878/

Hewitt, Robert and Bonj Szczygiel. 2000. "Nineteenth-century medical landscapes: John H. Rauch, Frederick Law Olmsted, and the search for salubrity," Bulletin of the History of Medicine 74, no. 4

Hill, Hibbert Winslow .1977. The New Public Health (New York: New York: Arno Press,), 9.

Hruby, Adela and Frank Hu. 2015. "The Epidemiology of Obesity: A Big Picture," PharmacoEconomics 33, no. 7, https://doi.org/10.1007/s40273-014-0243-x.

Jackson, Richard, Andrew Dannenberg, and Howard Frumkin, 2013. "Health and the built environment: 10 years after," American Journal of Public Health 103, no. 9.

Johns Hopkins University \& Medicine. “Coronavirus Resource Center.” https://coronavirus.jhu.edu/map.html. Accessed July 10, 2020.

Kearns, Robin. 1993. "Place and Health: Towards a Reformed Medical Geography" Professional Geographer 45, no. 2: 139-47.

Koch, Tom. 2005. Cartographies of Disease : Maps, Mapping, and Medicine. 1st ed. Redlands, Calif.: ESRI Press, , p. 236. 
Koch, Tom. 2012. "The Art of Medicine: Knowing Its Place: Mapping as Medical Investigation," The Lancet 379, no. 9819: 887-8.

Koch, Tom. 2011. Disease Maps: Epidemics on the Ground. Chicago: University of Chicago Press.

Kwan, Mei-Po. 2018. "The Limits of the Neighborhood Effect: Contextual Uncertainties in Geographic, Environmental Health, and Social Science Research." Annals of the American Association of Geographers 108, no. 6: 1482-490.

Kwan, Mei-Po. 2012. "How GIS Can Help Address the Uncertain Geographic Context Problem in Social Science Research." Annals of GIS 18, no. 4: 245-55

Lam, Nina Siu-Ngan. 2012. "Geospatial Methods for Reducing Uncertainties in Environmental Health Risk Assessment: Challenges and Opportunities." Annals of the Association of American Geographers 102, no. 5: 942-50.

Leinberger, Christopher and Patrick Lynch. 2016. Foot Traffic Ahead: Ranking Walkable Urbanism in America's Largest Metros. Washington, D.C.: George Washington University, http://www.smartgrowthamerica.org/documents/foot-traffic-ahead-2016.pdf.

Lopez, Russ P. 2009. "Public health, the APHA, and urban renewal." American Journal of Public Health 99, no. 9 : 1603-1611.

Los Angeles Department of City Planning. 2013. "PLAN for a Healthy Los Angeles: Interactive Map”, http://healthyplan.la/interactive/city/. Accessed July 2019.

Lubar. Steven. 1986."Trolley Lines, Land Speculation and Community-Building the Early History of Woodside Park, Silver Spring, MD", Maryland Historical Magazine

Maclachlan, John C., Michael Jerrett, Tom Abernathy, Malcolm Sears, and Martin J Bunch. 2007. "Mapping Health on the Internet: A New Tool for Environmental Justice and Public Health Research." Health and Place 13, no. 1: 72-86.

Manke, Kara. 2019. “Historically redlined communities face higher asthma rates,” Berkeley News, May 22, https://news.berkeley.edu/2019/05/22/historically-redlined-communities-face-higher-asthma-rates/

Marx, Leo. 2008. "The idea of nature in America," Daedalus 137, no. 2: 8-21. https://doi.org/10.1162/daed.2008.137.2.8.

Mcconnell, Shean. "Urban Renewal in the United States." Official Architecture and Planning 31, no. 2 (1968): 204-11. 
McLeod, Kari . 2000."Our Sense of Snow: The Myth of John Snow in Medical Geography," Social Science \& Medicine 50, no. 7-8: 923-35.

Melosi, Martin V. 2008. The Sanitary City : Environmental Services In Urban America From Colonial Times To The Present, (Pittsburgh, Pa.: the University of Pittsburgh Press).

Mitman, Gregg . 2003, "Hay Fever Holiday: Health, Leisure, and Place in Gilded-Age America," Bulletin of the History of Medicine 77, no. 3. https://doi.org/10.1353/bhm.2003.0127.

Moser, David. 2013. "Driven into Poverty: Walkable urbanism and the suburbanization of poverty," CityTank.org, , http://citytank.org/2013/03/08/driven-into-poverty-walkable-urbanism-and-the-suburbanizationof-poverty/

Openshaw, Stan . 1984. “The Modifiable Areal Unit Problem.” Concepts and Techniques in Modern Geography, No. 38. Norwich: Geo

Rosenberg, Mark. 1998. "Medical or Health Geography? Populations, Peoples and Places." International Journal of Population Geography 4, no. 3: 211-26, p. 219

Rosenberg, Charles E. 1987. The Cholera Years: the United States in 1832, 1849, and 1866 (Chicago: University of Chicago Press), p. 6.

Sampson, Robert. 2003. “Neighborhood-Level Context and Health: Lessons from Sociology,” in Kawachi, Ichiro, and Berkman, Lisa F., eds. Neighborhoods and Health. New York: Oxford University Press, p. pp 132146.

Shah, Nayan. Contagious Divides: Epidemics and Race in San Francisco's Chinatown. (Berkeley: University of California Press, 2001.)

Shanken, Andrew Michael. 2009. 194X Architecture, Planning, And Consumer Culture On The American Home Front (Minneapolis : University of Minnesota Press,), p. 70-74.

Susser, Mervyn and Ezra Susser, 1996. "Choosing a Future for Epidemiology: I. Eras and Paradigms." American Journal of Public Health 86, no. 5: 668-73.

Towne, Samuel, Won, Jaewoong, Lee, Sungmin, Ory, Marcia, Forjuoh, Samuel, Wang, Suojin, and Lee, Chanam. 2016, "Using Walk Score(TM) and Neighborhood Perceptions to Assess Walking Among MiddleAged and Older Adults." Journal of Community Health 41, no. 5: 977-88.

Valenčius, Conevery Bolton. 2002. The Health Of The Country : How American Settlers Understood Themselves And Their Land, New York : Basic Books 
Walkscore. “Cities and Neighborhoods.” https://www.walkscore.com/cities-and-neighborhoods/states/.

Accessed July 10, 2020.

Wallace, Rodrick, Deborah Wallace, et al. 1995. "The Spatiotemporal Dynamics of AIDS and TB in the New York Metropolitan Region from a Sociogeographic Perspective: Understanding the Linkages of Central City and Suburbs." Environment and Planning A 27, no. 7: 1085-108. 